\title{
PROEJA: ENTRE DESAFIOS E POSSIBILIDADES
}

\author{
D. H. MOURA' 1 e A. L S. HENRIQUE ${ }^{2}$ \\ ${ }^{1,2}$ Campus EAD - Instituto Federal do Rio Grande do Norte \\ E-mail: dante.moura@ifrn.edu.br ${ }^{1}$, ana.henrique@ifrn.edu.br ${ }^{2}$
}

Artigo submetido em maio/2012 e aceito em maio/2012

\section{RESUMO}

Neste trabalho, pesquisa-se a gênese e os anos iniciais de vigência do Programa de Integração da Educação Profissional à Educação Básica na Modalidade Educação de Jovens e Adultos - PROEJA - que visa oferecer oportunidades educacionais que integrem, na modalidade educação de jovens e adultos, o ensino médio à educação profissional técnica de nível médio ou o ensino fundamental à formação inicial e continuada de trabalhadores. Por meio de revisão bibliográfica e análise de documentos, analisa-se o Programa, enfocando os equívocos em sua implantação, suas possibilidades e desafios. Vale salientar que apesar de o PROEJA abranger a integração da educação profissional à educação básica, neste trabalho, a análise está concentrada na integração entre os cursos técnicos de nível médio e o ensino médio.

PALAVRAS-CHAVE: Ensino médio; educação profissional; educação de jovens e adultos; PROEJA

\section{PROEJA: ENTRE RETOS Y OPORTUNIDADES}

\section{RESUMEN}

En este trabajo, se investiga la génesis del Programa de Integración de la Educación Profesional a la Educación Básica en la Educación de Personas Jóvenes y Adultas - PROEJA - que busca ofertar oportunidades educativas que integren, en la educación de personas jóvenes y adultas, la enseñanza secundaria a la educación profesional técnica de nivel medio o la enseñanza fundamental a la formación de trabajadores.
Por medio de revisión bibliográfica y análisis documental, se evalúa el Programa, centrando la atención en los equívocos en su implantación, las posibilidades y los retos. Merece la pena decir que, pese a que el PROEJA trata de la integración de la Educación Profesional a toda la Educación Básica, en este trabajo, el análisis se centra en la integración entre los cursos técnicos de nivel medio y la enseñanza secundaria.

PALABRAS-CLAVE: Enseñanza secundaria; educación profesional; educación de personas jóvenes y adultas; PROEJA. 


\section{PROEJA: ENTRE DESAFIOS E POSSIBILIDADES}

\section{INTRODUÇÃO}

Conforme expresso no próprio nome, o Programa de Integração da Educação Profissional à Educação Básica na Modalidade Educação de Jovens e Adultos - PROEJA - visa oferecer oportunidades educacionais tanto a jovens e adultos que ainda não finalizaram o ensino fundamental, como àqueles que já o completaram, mas que não concluíram nem o ensino médio nem um curso que os habilite em uma profissão técnica de nível médio.

Neste trabalho, tem-se um duplo objetivo: a) analisar o processo de gênese e os dois primeiros anos de implementação desse Programa, enfocando suas possibilidades de contribuir para a melhoria das ofertas educacionais destinadas ao público da educação de jovens e adultos EJA; e b) analisar as limitações inerentes a esse processo. Para alcançar esse fim, foi realizada revisão bibliográfica e análise de documentos.

Para melhor localizar o leitor, importa esclarecer que, além dessa breve introdução, em que se buscar situar o leitor em relação ao objetivo deste estudo, o texto está organizado em 5 partes. No item 2, delimita-se o objeto de estudo - as singularidades da EJA e do PROEJA; no item 3, apresentam-se os principais equívocos que marcaram a gênese do Programa e alguns ajustes realizados no processo; no item 4, discutem-se alguns resultados significativos alcançados e algumas dificuldades encontradas no processo de implantação de cursos técnicos de nível médio integrados ao ensino médio na modalidade EJA, no âmbito do Programa ora em discussão; finalmente, nas considerações finais, salienta-se a importância de transformar o PROEJA em política educacional pública do estado brasileiro com seus correspondentes mecanismos de financiamento e o estabelecimento de um regime de cooperação mútua entre as esferas municipal, estadual e federal para dar sustentação às ofertas que o integram. Além disso, ressalta-se o imperativo de recriar práticas pedagógicas condizentes com as reais necessidades desses jovens e adultos em processo de educação escolar.

\section{DELIMITANDO O OBJETO DE ESTUDO}

No que diz respeito à educação básica de jovens e adultos no Brasil, pode-se afirmar que predominam iniciativas individuais ou de grupos isolados, acarretando descontinuidades, contradições e descaso dos órgãos responsáveis (MOURA, 2005). Por outro lado, a cada dia, aumenta a demanda social por políticas públicas perenes nessa esfera. Tais políticas devem pautar o desenvolvimento de ações baseadas em princípios epistemológicos que resultem em um corpo teórico bem estabelecido e que respeite as dimensões sociais, econômicas, culturais, cognitivas e afetivas do jovem e do adulto em situação de aprendizagem escolar (CABELLO, 1998).

Paralelamente, as instituições federais de educação profissional e tecnológica (EPT) ${ }^{1}$, convocadas a implantar o PROEJA, atuam no ensino médio integrado aos cursos técnicos tendo

\footnotetext{
${ }^{1}$ Rede Federal de Educação Profissional e Tecnológica, formada pelos centros federais de educação tecnológica (CEFETs), escolas técnicas federais (ETFs), escolas agrotécnicas federais (EAFs) e escolas técnicas vinculadas às universidades federais.
} 
como grupos destinatários os adolescentes recém concluintes do ensino fundamental, mas, historicamente, a grande maioria dessas instituições não havia atuado na modalidade EJA, até o surgimento do PROEJA. Enquanto isso, nas redes estaduais, também convidados a participar no PROEJA, há atuação na EJA e na EPT, mas não de forma integrada.

Segundo os documentos oficiais (BRASIL, 2006a), o PROEJA surge, então, com uma dupla finalidade. A primeira é enfrentar as descontinuidades e o voluntarismo que marcam a modalidade EJA no Brasil, e, a segunda, integrar à educação básica uma formação profissional que contribua para a integração socioeconômica de qualidade do coletivo de jovens e adultos.

Apesar de o PROEJA abranger a integração da educação profissional à educação básica, o que inclui o ensino fundamental e o ensino médio, assim como a formação inicial e continuada de trabalhadores e a educação profissional técnica de nível médio, neste trabalho, a análise está concentrada na integração entre os cursos técnicos de nível médio e o ensino médio, pois essas são as ofertas educacionais implantadas, no âmbito do PROEJA ${ }^{2}$, até o momento da realização deste estudo.

Um dos grandes desafios do Programa é integrar três campos da educação que historicamente não estão muito próximos: o ensino médio, a formação profissional técnica de nível médio e a educação de jovens e adultos. Igualmente desafiante é conseguir fazer com que as ofertas resultantes do Programa efetivamente contribuam para a melhoria das condições de participação social, política, cultural e no mundo do trabalho desses coletivos, em vez de produzir mais uma ação de contenção social. Coloca-se ainda outro desafio em um plano mais elevado: a transformação desse Programa em política educacional pública do estado brasileiro.

$\mathrm{E}$, finalmente, como uma utopia necessária, o desafio de que, no futuro mediato, mas não muito remoto, seja possível que o estado brasileiro efetivamente garanta aos filhos de todas as famílias, independentemente da origem socioeconômica, o acesso, a permanência e a conclusão da educação básica numa perspectiva politécnica ou tecnológica, com qualidade e de forma universalizada, na faixa etária denominada regular ${ }^{3}$. Ao alcançar essa universalização, a EJA poderá assumir outro papel: em vez de se destinar à formação inicial, poderá centrar-se na formação continuada da classe trabalhadora e, portanto, na capacitação com vistas ao exercício de atividades mais complexas dentre as profissões técnicas de nível médio e, inclusive, como forma de contribuir para o acesso à educação superior. Claro que, para alcançar esse estágio, algumas décadas serão necessárias. Mas, para que isso ocorra, mesmo em um momento do futuro impossível de ser previsto agora, é necessário que políticas como as tratadas neste documento sejam efetivamente construídas e postas em prática.

Nesse contexto, as instituições federais de educação, incluindo a Rede Federal de Educação Profissional de Tecnológica, têm papel relevante. Algumas características dessa Rede Federal de EPT potencializam a função que as instituições a ela vinculadas podem assumir nesse processo. Em primeiro lugar, estão presentes em quase todos os estados da federação. Em segundo, mas não com menor importância, está a experiência e a qualidade com que

\footnotetext{
${ }^{2}$ Quanto à integração entre a formação profissional e o ensino fundamental e a formação inicial e continuada de trabalhadores, foi publicado, em setembro de 2007, o respectivo Documento Base (BRASIL, 2007).

${ }^{3}$ A denominação regular para referir-se tanto à faixa etária como à modalidade já traz pressuposto um duplo preconceito: contra a modalidade EJA e contra os sujeitos aos quais ela se destina. Por isso, quando, ao longo do texto, esse termo for utilizado para tratar da EJA em comparação com a educação proporcionada aos sujeitos no tempo criança ou no tempo adolescente, será grafado em itálico com o objetivo de explicitar a discordância dos autores com o duplo preconceito antes mencionado.
} 
reconhecidamente atuam no ensino médio e na educação profissional técnica de nível médio.

A partir da vigência da Lei № 3.552/1959, as instituições que deram origem aos atuais institutos federais passaram a oferecer cursos na última etapa da educação básica - atual Ensino Médio - e cursos técnicos de nível médio. Em alguns momentos históricos, essa oferta ocorreu de forma integrada, ainda que essa integração não tenha acontecido em toda a plenitude de seu significado. Em outros momentos, ela ocorreu de forma separada, ou seja, ensino médio por um lado e cursos técnicos de nível médio por outro. De qualquer maneira, nas últimas quatro ou cinco décadas, essas ofertas educacionais estiveram presentes no âmbito da Rede Federal de EPT. Essa experiência associada à reconhecida qualidade dos cursos oferecidos em todo o país a qualifica como locus importante na fase inicial de implantação do PROEJA.

Por outro lado, ratifica-se que é pouca ou quase nenhuma a experiência da mencionada Rede no que se refere ao trabalho com a modalidade Educação de Jovens e Adultos, o que resulta em limitações a esse processo.

\section{PROEJA: EQUÍVOCOS QUE MARCARAM SUA GÊNESE E AJUSTES NO PROCESSO}

As intenções explicitadas no PROEJA são coerentes com as políticas públicas para a educação profissional e tecnológica definidas pelo atual governo federal (BRASIL, 2004), as quais apontam para a necessidade de a EPT articular-se com a educação básica e com o mundo do trabalho, além de interagir com outras políticas públicas, com o fim de contribuir para a garantia do direito de acesso de todos à educação básica, para o desenvolvimento socioeconômico e para a redução das desigualdades sociais. Igualmente, são coerentes com o Decreto № 5.154/2004, que revogou o Decreto № 2.208/1997 do governo FHC, o qual determinava a separação obrigatória entre o ensino médio e a educação profissional técnica de nível médio. Assim, o Decreto № 5.154/2004 entrou em vigor precisamente para permitir a integração entre o ensino médio e a educação profissional técnica de nível médio, aspecto fundamental para a implementação de uma política pública de EPT voltada para a formação integral dos cidadãos ${ }^{4}$.

Apesar dessas intenções explícitas no Programa e das potencialidades da Rede Federal de EPT em contribuir com seu êxito, alguns equívocos importantes marcam a gênese dessa iniciativa governamental. Em primeiro lugar, tem-se a instituição da Portaria №. 2.080/2005-MEC, de junho de 2005, que deu materialidade ao tema. Esse dispositivo determinava que todas as instituições federais de EPT oferecessem, a partir de 2006, cursos técnicos integrados ao ensino médio na modalidade EJA, estipulando, inclusive, um percentual mínimo de vagas que deveriam ser destinadas à nova oferta. Entretanto, legalmente uma portaria não pode ferir um decreto, que tem maior hierarquia e havia o Decreto №. 5.224/2004, que dispõe sobre a organização dos CEFETs ${ }^{5}$, o qual estabelece em seu artigo primeiro, que

\footnotetext{
${ }^{4}$ Para um maior aprofundamento com relação ao proceso de revogação do Decreto № 2.208/1997 e sua substituição pelo Decreto № 5.154/2004, sugerimos ver CIAVATTA, M.; FRIGOTTO, G.; RAMOS, M. N. A gênese do Decreto №. 5.154/2004: um debate no contexto controverso da democracia restrita. In: Trabalho necessário. Revista Eletrônica
} do Neddate. Disponível em <http://www.uff.br/trabalhonecessario/MMGTN3.htm>. Acesso em 09.08.2005.

${ }^{5}$ À época deste estudo, os CEFETs ainda não se haviam transformado em institutos federais. 
os centros federais de educação tecnológica - CEFETs -, criados mediante transformação das escolas técnicas federais e escolas agrotécnicas federais, [...] constituem-se em autarquias federais, vinculadas ao Ministério da Educação, detentoras de autonomia administrativa, patrimonial, financeira, didáticopedagógica e disciplinar. (BRASIL, 2004a, p. 1, grifo dos autores).

Dessa forma, a Portaria №. 2.080/2005-MEC carecia de legalidade.

Apesar das críticas veementes a diversos aspectos da supramencionada Portaria (№. 2.080/2005-MEC), após poucos dias de vigência, o seu conteúdo foi ratificado, quase integralmente, pelo Decreto №. 5.478/2005, que instituiu, no âmbito da Rede Federal de EPT, o PROEJA. Essa parece ter sido uma tentativa de resolver o problema de hierarquia das normas, mas o objetivo não foi alcançado, pois o Decreto №. 5.224/2004, mais antigo, permanece em pleno vigor.

Na esfera político-pedagógica, as poucas IFETs que ofereciam EJA à época da publicação do mencionado Decreto não o faziam na forma integrada à educação profissional. Dentre as experiências registradas na Rede, destacam-se as experiências dos hoje Institutos de Pelotas/RS, Santa Catarina, Espírito Santo, Campos/RJ e Roraima. Entretanto, em nenhum deles havia oferta integrada entre o ensino médio e a educação profissional técnica de nível médio. A maioria das iniciativas estava relacionada apenas à educação básica, enquanto algumas relacionavam educação básica e profissional na forma concomitante.

Diante desse quadro, é fácil constatar que não havia, na Rede Federal de EPT, um corpo de professores formados para atuar no campo específico da Educação de Jovens e Adultos nem no ensino médio propedêutico e, muito menos, no ensino médio integrado à educação profissional. Na verdade, em nenhum sistema de ensino brasileiro existem profissionais formados para atuar nessa nova oferta, pois, conforme mencionado inicialmente, trata-se de uma inovação educacional, de maneira que ainda não há formação sistemática de docentes para nela trabalhar.

Também cabe destacar que alguns institutos federais (à época CEFETs) oriundos de EAFs reduziram substancialmente o quadro docente do ensino médio nos últimos anos. Em algumas dessas instituições, em função do Decreto №. 2.208/1997 que, conforme explicitado, separou a oferta do ensino médio dos cursos técnicos, optou-se por extinguir a oferta do ensino médio. Dessa forma, o respectivo quadro de professores foi gradativamente sendo reduzido. Evidentemente, nessas instituições, simplesmente, não havia corpo docente suficiente sequer para oferecer cursos técnicos integrados ao ensino médio para os adolescentes egressos do ensino fundamental.

Diante desse panorama, não seria razoável exigir que a Rede passasse a reservar, obrigatoriamente, para os cursos do PROEJA, $10 \%$ de todas as vagas anuais destinadas aos cursos técnicos e cursos superiores de tecnologia, conforme estabelecido no Decreto № 5.478/2005.

Portanto, não é preciso grande esforço de análise dos fatos para constatar que essa matéria deveria ter sido estudada, aprofundada, discutida e avaliada em espaços mais amplos antes de vir à tona, sob pena de má utilização de recursos públicos e da não consecução dos objetivos explicitados. Caso isso tivesse ocorrido, se concluiria que, para que o PROEJA não fosse apenas uma ação isolada e, desse modo, pudesse contribuir para a construção de uma política 
educacional efetivamente comprometida com a melhoria das ofertas educacionais do campo da EJA, não poderia ser implementado apenas no âmbito da Rede Federal de EPT, posto que sua capacidade de oferta de vagas é minúscula diante da demanda nacional. É evidente que a concepção inicial deveria ter contemplado a participação das redes públicas estaduais e municipais de educação constitucionalmente consagrados à universalização do ensino fundamental e à contínua ampliação da oferta do ensino médio.

Essas questões aqui abordadas, além de outras, foram objeto de produção acadêmica apresentada em congressos científicos e publicada em periódicos especializados (MOURA, 2005; FRIGOTTO; CIAVATTA; RAMOS, 2005; entre outros).

Além disso, a própria Secretaria de Educação Profissional e Tecnológica - SETEC/MEC realizou, durante o segundo semestre de 2005, um conjunto de oficinas pedagógicas distribuídas pela geografia do país, cujo fim era promover a capacitação dos gestores acadêmicos das IFETs com vistas à implantação do PROEJA. Na verdade, essa ação, ao invés de concretizar a capacitação esperada, resultou em uma série de análises, reflexões e duras críticas relativas ao conteúdo e, principalmente, à forma de implantação do Programa.

Todo esse processo ocorreu simultaneamente a importantes mudanças na equipe dirigente da SETEC, no último trimestre de 2005, e o novo grupo mostrou-se sensível às críticas generalizadas provenientes do meio acadêmico e da Rede Federal de EPT. Desses fatos, resultaram alterações substantivas nos rumos da implantação do PROEJA na direção da construção de uma base sólida para a sua sustentação.

O primeiro passo, nessa nova fase, foi a constituição de um grupo de trabalho plural ${ }^{6}$ que teve a função de elaborar um Documento Base (BRASIL, 2006a) ${ }^{7}$ de concepções e princípios do Programa, até então inexistente, e cujo resultado aponta na direção de transformar esse Programa em política pública educacional.

Posteriormente, a partir das diretrizes apontadas por esse Documento Base, o Decreto № $5.478 / 2005$ foi substituído pelo Decreto 5.840/2006 (BRASIL, 2006b), atual instrumento legal regulador do PROEJA. Esse Decreto traz mudanças significativas em relação ao primeiro. Dentre elas destacam-se: a) a ampliação das cargas horárias dos cursos (o Decreto № 5.478/2005 estabelecia cargas horárias máximas para os cursos e, contrariamente, o Decreto № 5.840/2006 fixou limites mínimos, deixando a definição da carga horária a ser adotada em cada curso para o âmbito da autonomia da instituição ofertante); b) a ampliação dos espaços educacionais em que o PROEJA pode ser oferecido (o Decreto № 5.478/2005 limitava a oferta à Rede Federal de EPT, ao passo que o Decreto № 5.840/2006 incluiu as instituições públicas estaduais e municipais de educação também como espaço para as ofertas do PROEJA); c) a ampliação da abrangência do Programa (o Decreto № 5.478/2005 limitava o PROEJA ao ensino médio, enquanto o Decreto № $5.840 / 2006$ incluiu o ensino fundamental), englobando toda a educação básica.

\section{ALGUNS RESULTADOS SIGNIFICATIVOS E DIFICULDADES QUE AINDA PERSISTEM}

\footnotetext{
${ }^{6}$ Especialistas em EJA das universidades brasileiras, representantes da SETEC, da SECAD, dos fóruns de EJA, dos institutos federais (então CEFETs), das EAFs e das escolas técnicas vinculadas às universidades federais.

${ }^{7}$ No Documento Base do PROEJA, consta uma retrospectiva histórica sobre a educação de jovens e adultos no Brasil; uma análise dos problemas de acesso, permanência e qualidade da educação básica no País, tanto para o público denominado "regular" como na EJA. A partir daí, apresentam-se e discutem-se as concepções e os princípios do Programa.
} 
Algumas ações importantes foram sendo desencadeadas a partir das diretrizes emanadas do Documento Base (BRASIL, 2006a), dentre elas, merecem destaque a oferta de um curso de especialização voltado para a formação de profissionais do ensino público para atuar no PROEJA e as ações decorrentes do Edital PROEJA-CAPES/SETEC № 03/2006, destinado a estimular a realização de projetos conjuntos de pesquisa entre universidades federais e os então CEFETs, atuais institutos federais.

No que se refere aos cursos de especialização, tal iniciativa teve o objetivo de

\begin{abstract}
Formar profissionais com capacidades para atuar na elaboração de estratégias, no estabelecimento de formas criativas das atividades de ensino-aprendizagem e de prever pro-ativamente as condições necessárias e as alternativas possíveis para o desenvolvimento adequado da educação profissional técnica de nível médio integrada ao ensino médio na modalidade Educação de Jovens e Adultos, considerando as peculiaridades, as circunstâncias particulares e as situações contextuais concretas em que programas e projetos deste campo são implementados (BRASIL, 2006c, p. 8).
\end{abstract}

Dessa forma, a concepção dos diversos programas de especialização criados nos pólos distribuídos em todo o país fundamentou-se nos seguintes pressupostos (BRASIL, 2006c):

a) a necessidade da formação de um novo profissional que possa atuar na educação profissional técnica de nível médio integrada ao ensino médio na modalidade EJA como docente-pesquisador, gestor educacional de programas e projetos e formulador e executor de políticas públicas;

b) a integração entre trabalho, ciência, técnica, tecnologia, humanismo e cultura geral, a qual contribui para o enriquecimento científico, cultural, político e profissional dos sujeitos que atuam nessa esfera educativa, sustentando-se nos princípios da interdisciplinaridade, contextualização e flexibilidade, como exigência historicamente construída pela sociedade;

c) espaço para que os cursistas possam compreender e aprender uns com os outros, em fértil atividade cognitiva, afetiva, emocional, contribuindo para a problematização e a produção do ato educativo numa perspectiva sensível, com a qual a formação continuada de professores nesse campo precisa lidar.

Para alcançar os objetivos e as finalidades propostas, o currículo do curso foi voltado para a necessária integração entre os três campos educacionais: o ensino médio, a educação profissional técnica de nível médio e a educação de jovens e adultos. Dessa forma, nas Propostas Gerais para Elaboração de Projetos Pedagógicos de Curso de Especialização (BRASIL, 2006c), foi sugerido que os conteúdos programáticos fossem estruturados a partir dos seguintes eixos: concepções e princípios da educação profissional, do ensino médio e da educação de jovens e adultos; gestão democrática; políticas e legislação educacional; concepções curriculares em educação profissional, no ensino médio e na educação de jovens e adultos; e didáticas na educação profissional, no ensino médio e na educação de jovens e adultos.

Essa medida foi o ponto de partida por meio do qual, segundo dados da SETEC, foram formados mais de 3000 profissionais nos pólos constituídos e distribuídos pelo país, a partir de 
2006. Com relação a esses cursos, é preciso destacar que, em um primeiro momento, as ações tiveram continuidade, mas a oferta vem sendo interrompida, em alguns pólos, na medida em que o MEC interrompeu o financiamento de novas turmas. Isso demonstra que nessas instituições o incentivo inicial do MEC não foi suficiente para institucionalizar esses cursos de especialização. Como exemplo, pode-se citar o IFRN que entre 2006 e 2009 abriu 14 turmas, todas com financiamento do MEC, mas que a partir de 2010 não criou novas turmas.

Na segunda ação destacada, o Edital Proeja-CAPES/SETEC no 03/2006, cujo objetivo é estimular a realização de projetos conjuntos de pesquisa, com a utilização de recursos humanos e de infraestrutura disponíveis em diferentes instituições de educação superior, incluída a rede federal de EPT, 09 projetos provenientes, principalmente, de consórcios entre universidades federais e IFs encontram-se em fase de conclusão ou foram concluídos. Essa ação visa à produção de conhecimentos por meio de pesquisas e a formação de pessoal pós-graduado em EP integrada à educação de jovens e adultos, contribuindo, assim, para desenvolver e consolidar as proposições curriculares e organizativas na área. Como se vê, os cursos de especialização e as ações inerentes ao Edital Proeja-CAPES/SETEC estão voltados, dentre outros aspectos, para a formação de um corpo de formadores de futuros formadores na perspectiva de desencadear processos institucionais voltados para a formulação, gestão e execução de cursos de EMI na modalidade EJA.

Como se vê, os cursos de especialização e as ações inerentes ao Edital PROEJACAPES/SETEC estão voltados, dentre outros aspectos, para a formação de um corpo de formadores de futuros formadores, profissionais que poderão desencadear processos institucionais voltados para a formulação, gestão e execução de cursos de ensino médio integrado na modalidade EJA, assim como para a criação de grupos de pesquisa voltados para a produção do conhecimento nesse campo.

Apesar desses avanços, que apontam para possíveis melhorias a médio e longo prazo, o processo de implantação do Proeja na rede federal, nos estados e nos municípios não está alcançando plenamente os objetivos previstos.

Vários aspectos contribuem para um quadro preocupante, dentre eles: a falta de processos sistemáticos de formação continuada dos docentes; a ausência de discussões mais qualificadas no interior das instituições acerca da concepção do EMI e da implantação do Programa; a forma impositiva como esse Programa entrou em vigor; os elevados índices de evasão; e uma visão elitista de parte dos profissionais que integram a rede federal, os quais vinculam a entrada do público da EJA nessas instituições a uma ameaça à qualidade do ensino ali existente. Dessa forma, esse conjunto de fatores está contribuindo significativamente para que haja uma parcial rejeição ao Programa no interior da rede, reforçando a visão preconceituosa em direção aos seus sujeitos. Evidentemente, esses aspectos têm estreita relação com a construção e o desenvolvimento do currículo nessas instituições.

Evidentemente, esse quadro deixa lacunas no pensar e no fazer pedagógico dos profissionais que atuam nessa área. Uma delas, que também é decorrente da falta de formação prévia dos professores, refere-se à produção de material didático específico para utilização no PROEJA. Historicamente, o material didático atende a um dos níveis, não considerando a integração entre a educação básica e o técnico de nível médio da esfera da educação profissional. Além disso, o material didático disponível e utilizado nos cursos técnicos de nível médio, em geral, tem talante instrumentalista, porque muitos desses cursos se preocupam, prioritariamente, 
em formar para o mercado de trabalho, na visão mais estreita que se pode ter desse termo, esquecendo que a formação profissional

extrapola a simples preparação para uma ocupação específica no mundo do trabalho e postula a vinculação entre a formação técnica e uma sólida base científica, numa perspectiva social e histórico-crítica, integrando a preparação para o trabalho à formação de nível médio (MANFREDI, 2002, p.57).

E pode-se acrescentar ainda que o material específico da EJA desconsidera as especificidades e diversidades desse público, entre as quais podem-se citar a faixa etária, os diversos níveis de maturidade intelectual, de experiência de vida e de domínio no uso dos recursos linguísticos. Em muitos desses materiais, o coletivo da EJA é tratado como uma criança grande, o que revela desconhecimento por parte dos profissionais que elaboram esse material de como aprende o adulto quando se encontra em situação escolar.

Outro grande desafio diz respeito à juvenilização do público de EJA. Para citar alguns exemplos, tomemos emprestados alguns dados de duas monografias defendidas em 2007, no âmbito do curso de especialização do PROEJA no IFRN. Gomes e Angelo (2007) e Henrique e Oliveira (2007) tiveram como objeto de suas pesquisas 4 cursos técnicos de nível médio integrados ao ensino médio na modalidade EJA, ministrados no estado do Rio Grande do Norte.

Gomes e Angelo (2007), analisando três turmas da educação técnica de nível médio integrada ao ensino médio na modalidade EJA - Técnico em Edificações, Técnico em Informática e Técnico em Enfermagem -, encontraram nos três grupos pesquisados uma maior incidência de matrículas na faixa etária de 18 a 24 anos. No curso de Edificações, o percentual chegou a 75\%, no curso de Enfermagem, 73\% e no de Informática, 66\%.

Henrique e Oliveira (2007), pesquisando o Curso Técnico em Controle Ambiental, perceberam que $68 \%$ dos estudantes estavam dentro da faixa etária anteriormente mencionada.

Esses dados revelam que a juvenilização do público de EJA no Estado do Rio Grande do Norte é um fenômeno concreto, o que vem ao encontro do que está ocorrendo no Nordeste e no Brasil.

Outro dado desafiador foi a distorção em relação à meta de elevação de escolaridade recomendada pelo Documento Base. As pesquisas supracitadas também analisaram o nível de escolaridade dos estudantes inscritos nos 4 cursos. No Curso de Controle Ambiental, $82 \%$ das vagas foram preenchidas por pessoas que ou haviam concluído ou estavam cursando o ensino médio. No Curso de Edificações, esse percentual chegou a 97,5\%; no Técnico em Enfermagem, atingiu 93,3\%; e no Curso Técnico em Informática, 75\%. É importante registrar ainda que havia um percentual de alunos com o ensino médio profissionalizante completo (8,3\%, em Informática, e 2,5\%, em Edificações) ou com o ensino superior incompleto (4,2\%, em Informática).

Se considerarmos que o Documento Base (BRASIL, 2006a) recomenda que a oferta de cursos tenham como meta a elevação da escolaridade, esses dados podem ser vistos como uma distorção em relação à recomendação do PROEJA. Isso indica que os processos de seleção para ingresso nos cursos oferecidos pelo Programa podem estar priorizando os conhecimentos dos candidatos, excluindo precisamente o público-alvo do Programa que necessita da elevação da escolaridade - objetivo central do PROEJA -, ou seja, segundo os objetivos do Programa as vagas 
deveriam ser destinadas aos sujeitos que não concluíram a educação básica.

Esse procedimento revela a prática da inclusão excludente, já que são excluídos, via processo de seleção com vistas ao ingresso, os sujeitos que integram o público prioritário do Programa, precisamente, por estarem em condições mais adversas do ponto de vista do acesso à educação escolar. Ou dito de outra forma, é evidente que os indivíduos que já concluíram o ensino médio tiveram mais oportunidades educacionais do que aqueles que só finalizaram o ensino fundamental. Além disso, há que se considerar o (re)trabalho, posto que os estudantes que já concluíram o ensino médio e ingressam no PROEJA vão repetir, em princípio, os estudos relativos a essa etapa educacional.

Entretanto, a situação concreta se apresenta ainda mais preocupante, pois, em que pese o grau de escolaridade desses estudantes, esse fato não se refletiu no nível de conhecimento dos conteúdos formais relativos ao ensino fundamental e ao ensino médio.

Nesse sentido, alguns depoimentos de estudantes que já haviam concluído o ensino médio ao entrarem em uma oferta do PROEJA nos cursos Técnicos em Edificações, em Informática e em Enfermagem revelam sua busca por refazer o ensino médio em uma escola de qualidade, conforme exemplificado a seguir:

Dep.1: Eu resolvi fazer porque gostaria de ter um ensino médio melhor do que eu fiz, porque eu estudei em escolas públicas e gostaria muito de fazer um melhor (entrevistado 37)

Dep.2: Para melhorar um pouco mais meus conhecimentos do ensino médio [...](entrevistado 5)

Dep.3: [...] o CEFET oferece um ensino médio excelente dando oportunidade de fazer vestibular em qualquer instituição superior. (entrevistado 30)

Dep.4: O CEFET oferece melhor estudo e grátis (entrevistado 30) (GOMES e ANGELO, 2007, p. 65-66):

Especificamente, no curso Técnico em Controle Ambiental, também se verificou que o grau de escolaridade declarado não correspondia necessariamente ao equivalente grau de conhecimento. Essa disparidade gerou uma enorme dificuldade durante o desenrolar de todo o processo pedagógico, especialmente no caso das professoras de Língua Portuguesa. Conforme expressam as pesquisadoras,

Os alunos apresentavam perfis muito diversificados, tanto no que se refere a conhecimentos específicos dos conteúdos, quanto ao domínio da própria língua. Assim, alguns encontram-se ainda na fase pré-silábica, confundindo a pronúncia de letras e de sílabas e soletrando cada sílaba para só então pronunciar as palavras; outros já conseguiam ler frases inteiras, mas não pareciam compreender o que estavam lendo; outros ainda liam e compreendiam pequenos trechos, mas apenas num nível muito superficial; outros, porém, conseguiam ler, compreender e interpretar textos curtos de vocabulário simples; outros, finalmente, liam, compreendiam, interpretavam, faziam analogias e discutiam com segurança ideias e textos de um maior grau de complexidade. No que se refere à escrita, esse quadro se repetia e os níveis variavam dos que ainda desenhavam as palavras até os que já tinham uma autonomia relativa para produzir 
textos, a partir das situações propostas (HENRIQUE; OLIVEIRA, 2007, p. 25-26).

Essa descrição demonstra o descompasso entre o grau de escolaridade e o domínio do conhecimento que os estudantes têm de fato - e esse é outro grande desafio do PROEJA -, o que exige metodologias diversificadas e material didático específico para o fazer pedagógico. Esse fato é ainda mais desafiador quando, na seleção, priorizam-se os estudantes que têm apenas o ensino fundamental completo, público-alvo do PROEJA. Percebeu-se que eles não tinham a mínima condição de acompanhar o curso por falta dos conhecimentos do ensino fundamental.

Outro ponto que merece discussão é a reduzida carga horária dos cursos, cuja exigência de carga horária máxima, em função do primeiro Decreto regulador ( $n$ o 5.478/2005), produziu certo encurtamento dos currículos, provocando seu empobrecimento. Essa redução, muitas vezes, ocorreu nos conteúdos das disciplinas da formação propedêutica, o que, de certa forma, dificulta a formação integral do cidadão e impede que a educação na modalidade EJA cumpra as suas funções reparadora e equalizadora (BRASIL, 2000). Isso, ao invés de consolidar o PROEJA como uma oferta de qualidade, reproduz a ideia de que a EJA é uma modalidade compensatória, destinada a cidadãos de segunda categoria (HADDAD, 2005).

Deve-se ainda ressaltar o alto índice de evasão registrado nos cursos da modalidade EJA em todo o Brasil. Em que pese o crescente número de matrículas na modalidade em questão (em 1999, eram 3.071.906 passando para 5.616.291, em 2006,) em todos os níveis de ensino, a permanência desses alunos na escola é ainda um problema. Em geral, a alta taxa de evasão tem origem no uso de material didático inadequado para a faixa etária, nos conteúdos sem significado, nas metodologias infantilizadas aplicadas por professores despreparados e em horários de aula que não respeitam a rotina de quem estuda e trabalha.

Também no PROEJA se está reproduzindo essa elevada evasão. Apesar de, no âmbito nacional, ainda não existirem dados consolidados a esse respeito, as primeiras informações proporcionadas pela SETEC e pelas instituições ofertantes ratificam no PROEJA o que vem ocorrendo historicamente na EJA.

Por fim, é preciso destacar a reprodução da lógica perversa de que a EJA é compensatória e uma educação pobre destinada aos pobres. Mesmo em um processo com avanços significativos como alguns destacados ao longo deste documento, em momentos decisivos, aflora a racionalidade dominante que resiste em prover as condições necessárias a proporcionar acesso a uma educação de qualidade para todos. Na esfera do PROEJA, o episódio mais recente em que se manifestou essa lógica foi a Lei № 11.494, de 20/06/2007, que regulamenta o Fundo de Manutenção e Desenvolvimento da Educação Básica e de Valorização dos Profissionais da Educação (FUNDEB).

Nesse instrumento legal, são definidos, para o primeiro ano de vigência do FUNDEB, os valores mínimos que serão destinados, por aluno, em função da esfera educacional (educação infantil, ensino fundamental ou médio). Também há diferenciação em função da modalidade e da localização da escola (urbana ou rural). O valor utilizado como referência foi o destinado a cada estudante das séries iniciais do ensino fundamental urbano, no ano de 2006, pelos critérios do extinto FUNDEF. A partir desse valor (que recebeu a ponderação 1,0), foram criadas outras ponderações conforme a especificidade de cada oferta educacional.

O Artigo 36 da mencionada Lei é o que estabelece tais ponderações, conforme transcrito 
em seguida:

Art. 36. No $1^{\underline{0}}$ (primeiro) ano de vigência do FUNDEB, as ponderações seguirão as seguintes especificações:

I - creche - 0,80 (oitenta centésimos);

II - pré-escola - 0,90 (noventa centésimos);

III - anos iniciais do ensino fundamental urbano - 1,00 (um inteiro);

IV - anos iniciais do ensino fundamental no campo - 1,05 (um inteiro e cinco centésimos);

V - anos finais do ensino fundamental urbano - 1,10 (um inteiro e dez centésimos);

VI - anos finais do ensino fundamental no campo - 1,15 (um inteiro e quinze centésimos);

VII - ensino fundamental em tempo integral - 1,25 (um inteiro e vinte e cinco centésimos);

VIII - ensino médio urbano - 1,20 (um inteiro e vinte centésimos);

IX - ensino médio no campo - 1,25 (um inteiro e vinte e cinco centésimos);

$X$ - ensino médio em tempo integral - 1,30 (um inteiro e trinta centésimos);

XI - ensino médio integrado à educação profissional - 1,30 (um inteiro e trinta centésimos);

XII - educação especial - 1,20 (um inteiro e vinte centésimos);

XIII - educação indígena e quilombola - 1,20 (um inteiro e vinte centésimos);

XIV - educação de jovens e adultos com avaliação no processo - 0,70 (setenta centésimos);

XV - educação de jovens e adultos integrada à educação profissional de nível médio, com avaliação no processo - 0,70 (setenta centésimos).

$\S 1^{\circ}$ A Comissão Intergovernamental de Financiamento para a Educação Básica de Qualidade fixará as ponderações referentes à creche e pré-escola em tempo integral.

$\S 2^{\circ} \mathrm{Na}$ fixação dos valores a partir do $2^{\circ}$ (segundo) ano de vigência do FUNDEB, as ponderações entre as matrículas da educação infantil seguirão, no mínimo, as seguintes pontuações:

I - creche pública em tempo integral - 1,10 (um inteiro e dez centésimos);

II - creche pública em tempo parcial - 0,80 (oitenta centésimos);

III - creche conveniada em tempo integral - 0,95 (noventa e cinco centésimos);

IV - creche conveniada em tempo parcial - 0,80 (oitenta centésimos);

$\mathrm{V}$ - pré-escola em tempo integral - 1,15 (um inteiro e quinze centésimos);

VI - pré-escola em tempo parcial - 0,90 (noventa centésimos).

(BRASIL, 2007b. Negrito dos autores).

Observe-se, primeiro, a ponderação dada à educação de jovens e adultos com avaliação no processo, expressa no item XIV: 0,70 (setenta centésimos). Uma rápida olhada comparativa entre ela e a dos demais itens mostra que 0,70 é a menor ponderação entre as especificadas. Tal destinação, no mínimo, aponta para a manutenção do descaso histórico em relação à modalidade, o que confirma a lógica anteriormente comentada (educação pobre para os mais pobres).

Mais especificamente, observem-se os itens XI e XV do artigo acima transcrito, em que, mais uma vez, se constata a reprodução da lógica perversa. Na verdade, ambos referem-se à integração entre o ensino médio e a educação profissional técnica de nível médio. A única diferença é que no inciso XI trata-se da oferta dirigida aos adolescentes que estão realizando seus cursos na denominada faixa etária regular, enquanto o inciso XV é relativo à mesma oferta educacional dirigida ao público da modalidade EJA. É preciso ver que a ponderação da primeira oferta é a maior $(1,30)$, enquanto a da mesma oferta na modalidade EJA é precisamente a menor 
entre todas as ponderações $(0,70)^{8}$.

O problema não reside no fato de a ponderação do inciso XI ser a mais elevada, mas na diferença entre elas. Assim, cabe perguntar: que diferenças de infraestrutura física, de recursos humanos ou de outra ordem podem existir entre o ensino médio integrado dirigido aos adolescentes e o destinado ao público EJA que justifiquem tal diferenciação?

Poder-se-ia tentar justificar pela possível diferença entre a carga horária prevista para os cursos técnicos integrados destinados ao público EJA e a destinada aos mesmos cursos oferecidos na modalidade regular, uma vez que o Art. 4ㅇdo Decreto № 5.840/2006 prevê uma carga horária mínima de 2.400 horas para a modalidade EJA, enquanto a Resolução CNE № 1/2005 prevê uma carga horária mínima de 3.000 horas para os cursos de educação profissional técnica de nível médio realizados de forma integrada com o ensino médio para os alunos na faixa etária regular.

Entretanto, tal justificativa não se sustenta e pode ser contestada com dois argumentos. Em primeiro lugar, o dispositivo legal que prevê essa redução (Decreto № 5.840/2006) não pode ser aplicado de forma linear, pois se é verdade que os sujeitos adultos podem trazer experiências da vida, das práticas sociais, inclusive do mundo do trabalho, que lhes permitam avançar mais rapidamente nos processos de educação escolar que os adolescentes, também é verdade que nem todos os adultos tiveram essas oportunidades e, portanto, nem todos podem abreviar seu tempo de educação escolar, garantindo a qualidade dessa formação. Além disso, há que se atentar para o fenômeno de juvenilização da EJA que está levando muitos adolescentes para essa modalidade tanto no ensino fundamental (idade mínima 15 anos) como no ensino médio (idade mínima 18 anos), os quais, em geral, ainda não acumularam essas experiências de vida.

O segundo argumento está na relação entre a possível redução da carga horária para os cursos técnicos de nível médio integrados ao ensino médio destinados ao público EJA e o percentual aplicado na ponderação do custo aluno dado à educação profissional nas duas ofertas (a dita regular e a EJA). A carga horária mínima da oferta regular, em nenhuma situação, pode ultrapassar 33,3\% em relação à carga horária mínima da modalidade EJA, já que a mínima prevista para essa modalidade é de 2.400 horas (Art. 4 으 do Decreto № 5.840/2006) enquanto na oferta regular a maior carga horária mínima pode alcançar 3.200 horas (Art. 5ำ da Resolução CNE № 1/2005) nos cursos das áreas profissionais em que a carga horária mínima da formação profissional é de 1.200 horas. No entanto, a transcrição do Artigo 36 da Lei № 11.494/2007 mostra que a ponderação utilizada para a oferta regular é $86 \%$ maior do que a aplicada à modalidade EJA, consolidando a lógica perversa de educação mais barata e, portanto, mais pobre para os que têm maior dificuldade de acesso à escola e de permanência na educação escolar.

\section{CONSIDERAÇÕES FINAIS}

Quase a modo de revisão, as considerações finais estão centradas na importância da construção de uma política educacional pública e dos correspondentes mecanismos de financiamento para dar sustentação às ofertas integrantes do PROEJA, sem o que se corre o risco de trazer à tona e destinar recursos públicos a mais um programa focal e contingente no âmbito da EJA como já o são a Escola de Fábrica e o PROJOVEM, para mencionar apenas algumas

${ }^{8}$ Em 2011,essa ponderação foi alterada para 0,80 por meio da Portaria no 1.322/2011-MEC. HOLOS, Ano 28, Vol 2 
iniciativas na esfera federal de governo.

Para que tal política tenha a possibilidade de êxito, reafirma-se a necessidade de interação entre as redes públicas de educação federal, estaduais e municipais, no sentido de buscar a integração entre o ensino básico, a educação profissional técnica de nível médio e a EJA com vistas à construção de um novo campo educacional que terá elementos desses três, mas que não será apenas sua somatória. Dito de outra maneira, essa esfera educacional deve ter identidade própria, constituindo-se em um novo objeto de estudo que demandará métodos específicos, material didático específico, adequação dos horários ao grupo a que se destina, formação dos agentes educacionais envolvidos (professores, pedagogos e gestores). Isso implica em clareza teórica, na vontade política e no compromisso ético com a cidadania conscientizada e emancipada dos grupos destinatários (FREIRE, 2005).

À Rede Federal de EPT cabe, nesse esforço conjunto, priorizar a ampliação de vagas do ensino médio integrado tanto para o público EJA como para os adolescentes egressos do ensino fundamental. Paralelamente, ratifica-se que também é papel irrenunciável dessa Rede a aproximação às respectivas redes estaduais de educação, no sentido estabelecer um regime de mútua colaboração que contribua para a efetivação de ações estruturantes no campo da EPT. Dentre essas ações, destacam-se a formação de docentes; a elaboração de projetos políticopedagógicos e de planos de cursos dos centros de EPT; a constituição e a estruturação de grupos de pesquisa voltados para a construção do conhecimento no âmbito dessa esfera educacional; o desenvolvimento de estudos que possam contribuir para a definição dos cursos a serem oferecidos, considerando-se as necessidades e características dos destinatários e o desenvolvimento socioeconômico local, além de outras inerentes a cada realidade local.

Finalmente, cabe ressaltar o significativo alcance socioeconômico que pode ter o PROEJA, caso seja transformado em política pública a ser implementada nas redes públicas da União, dos Estados, dos municípios e do Distrito Federal por meio de processos participativos, planejados e que integrem essas distintas esferas educacionais.

\section{REFERÊNCIAS}

1. BRASIL. Decreto № 5.840, de 23 de julho de 2006. Institui, no âmbito federal, o Programa de Integração da Educação Profissional com a Educação Básica na Modalidade de Educação de Jovens e Adultos - PROEJA. Brasília, DF: 24 de junho de 2006b.

2. ___ Decreto № 5.478, de 24 de junho de 2005. Institui, no âmbito das instituições federais de educação tecnológica, o Programa de Integração da Educação Profissional ao Ensino Médio na Modalidade de Educação de Jovens e Adultos - PROEJA. Brasília, DF: 24 de junho de 2005a.

3. __. Decreto № 5.224, de 01 de outubro de 2004. Dispõe sobre a organização dos centros federais de educação tecnológica e dá outras providências. Brasília, DF: 23 de julho de 2004a.

4. __. Decreto № 5.154, de 23 de julho de 2004. Regulamenta o § 20 do Art. 36 e os arts. 39 a 41 da Lei № 9.394, de 20 de dezembro de 1996, que estabelece as diretrizes e bases da educação nacional. Brasília, DF: 23 de julho de 2004b. 
5. . Decreto № 2.208, de 17 de abril de 1997. Regulamenta o § 2ㅇ do Art. 36 e os arts. 39 a 41 da Lei № 9.394, de 20 de dezembro de 1996, que estabelece as diretrizes e bases da educação nacional. Brasília, DF: 17 de abril de 1997.

6. . MINISTÉRIO DA EDUCAÇÃO. Programa de Integração da Educação Profissional com a Educação Básica na Modalidade de Educação de Jovens e Adultos - PROEJA. Formação Inicial e Continuada/Ensino Fundamental. Documento Base, 2007. Disponível em <http://portal.mec.gov.br/setec/arquivos/pdf2/proeja_fundamental_ok.pdf> Acesso 04.10.2007.

7. MINISTÉRIO DA EDUCAÇÃO. Portaria № 2.080, de 13 de junho de 2005. Dispõe sobre diretrizes para a oferta de cursos de educação profissional de forma integrada aos cursos de ensino médio, na modalidade de educação de jovens e adultos - EJA no âmbito da rede federal de educação tecnológica. Brasília, DF: 13 de junho de 2005b.

8. MINISTÉRIO DA EDUCAÇÃO. Programa de Integração da Educação Profissional Técnica de Nível Médio Integrada ao Ensino Médio na Modalidade de Educação de Jovens e Adultos PROEJA. Documento Base, 2006a. Disponível em <http://portal.mec.gov.br/setec.> Acesso em 07.04.2006a.

9. _ MINISTÉRIO DA EDUCAÇÃO. Políticas públicas para a educação profissional e tecnológica. Brasília: abril de 2004. Disponível em <http://portal.mec.gov.br/setec/arquivos/pdf/p_publicas.pdf >. Acesso 11.07.2006b.

10. _. MINISTÉRIO DA EDUCAÇÃO. SECRETARIA DE EDUCAÇÃO PROFISSIONAL E TECNOLÓGICA Propostas Gerais para Elaboração de Projetos Pedagógicos de Curso de Especialização. Brasília: MEC/mimeo, 2006c.

11. CONSELHO NACIONAL DE EDUCAÇÃO. Parecer CNE/CEB №. 11/2000 e Resolução CNE/CEB №. 1/2000. Diretrizes Curriculares para a Educação de Jovens e Adultos. Brasília: MEC, maio 2000.

12. CONSELHO NACIONAL DE EDUCAÇÃO. Parecer CNE/CEB №. 1/2005. Atualiza as Diretrizes Curriculares Nacionais definidas pelo Conselho Nacional de Educação para o Ensino Médio e para a Educação Profissional Técnica de nível médio às disposições do Decreto № $5.154 / 2004$.

13. CABELLO, M. J. Aprender para convivir: concepciones y estrategias en educación de personas adultas. In Revista diálogos, vol 14. Madri, 1998.

14. FREIRE, P. Pedagogia do oprimido. 41 ed. Rio de Janeiro: Paz e terra, 2005.

15. FRIGOTTO, G.; CIAVATTA, M.; RAMOS, M. N. A gênese do Decreto №. 5.154/2004: um debate no contexto controverso da democracia restrita. In: Trabalho necessário. Revista Eletrônica do neddate. Disponível em <http://www.uff.br/trabalhonecessario/MMGTN3.htm>. Acesso em 09.08.2005

16.

A política de educação profissional no Governo Lula: um percurso histórico controvertido. Educ. Soc. [online]. out. 2005, vol.26, no.92 [citado 11 Julho 2006], p.10871113. Disponível em: <http://www.scielo.br/scielo.php?script=sci_arttext\&pid=S010173302005000300017\&Ing=pt\&nrm=iso>. ISSN 0101-7330. Acesso 11.07.06 
17. GOMES. C.O.; ANGELO. C.B.; Entre o oficial e o real: conhecendo os estudantes do Proeja. Natal, 2007, 77p. Monografia (Especialização). Diretoria de Ensino do Centro Federal de Educação Tecnológica do Rio Grande do Norte.

18. HADDAD, S. A educação de pessoas jovens e adultas e a nova LDB. IN: BREZINSKI, (Org.) LDB interpretada: diversos olhares se entrecruzam. 9 ed. São Paulo: Cortez, 2005, p. 111-127.

19. HENRIQUE. A. L. S.; OLIVEIRA. L. A. B.; Ações metodológicas e material didático com vistas à integração entre os conhecimentos materializados em disciplinas no curso técnico de nível médio integrado em controle ambiental na modalidade EJA. Natal, 2007, 77p. Monografia (Especialização). Diretoria de Ensino do Centro Federal de Educação Tecnológica do Rio Grande do Norte.

20. MANFREDI, S. M. Educação profissional no Brasil. São Paulo: Cortez, 2002.

21. MOURA, D. H. Reflexões sobre ética, estado brasileiro e educação. Mimeo: 2006.

22. Algumas considerações críticas ao Programa de Integração da Educação Profissional ao Ensino Médio na Modalidade de Educação de Jovens e Adultos - PROEJA. In: II COLÓQUIO INTERNACIONAL POLÍTICAS E PRÁTICAS CURRICULARES: impasses, tendências e perspectivas. Anais... João Pessoa: UFPB, 2005. 